\title{
Fenomenologia do corpo em Michel Henry: uma leitura a partir da imanência subjetiva
}

\author{
Phenomenology of the body in Michel Henry: \\ a reading from the subjective immanence
}

\section{Silvestre Grzibowski'}

\begin{abstract}
Resumo: O presente estudo visa apresentar o tema do corpo em Michel Henry mais especificamente, o corpo subjetivo a partir da imanência absoluta. As teorias clássicas e fenomenológicas investigaram a questão do corpo e deram suas contribuições, no entanto, foram constituídas a partir de uma relação transcendental. Para desenvolver o argumento do corpo subjetivo é fundamental compreender a noção de imanência, que será apresentada no primeiro momento da pesquisa. Posteriormente, será trabalhada a temática sobre o corpo subjetivo e por último, realizada uma contraposição com corpo transcendental. Assim, este ensaio busca sustentar a tese de que na fenomenologia de Henry existirá o corpo subjetivo desde que esse possa ser constituído a partir da imanência absoluta.
\end{abstract}

Palavras-chave: Michel Henry; Imanência; Corpo subjetivo; Corpo transcendental

\begin{abstract}
The present study aims to introduce the topic of body on Michel Henry more specifically, subjective body from the absolute immanence. Classic and phenomenological theories investigated the question of the body and gave their contributions, however, were formed from a transcendental ratio. To develop the argument of subjective body is essential to understand the concept of immanence, which will be presented at the first time of the research. Afterwards, will be crafted theme about the subjective body and finally held a contrast to transcendental body. So, this essay seeks to sustain the thesis that in the phenomenology of Henry subjective body will exist as long as this can be constituted from the absolute immanence.
\end{abstract}

Keywords: Michel Henry; Immanence; Subjective body; Transcendental body

\section{Introdução}

Apesar do tema do corpo ser pouco desenvolvido pela filosofia ocidental, a fenomenologia percebeu sua importância e o trouxe para o centro do debate filosófico. $\mathrm{Na}$ perspectiva da fenomenologia histórica o corpo não era considerado apenas um objeto, isso porque, Husserl nas descrições fenomenológicas diferenciava o corpo objeto do corpo próprio. A palavra Körper como corpo está ligada à dimensão física, da materialidade matematicamente qualificável. Como interpreta Depraz "quando Körper intervém em um contexto humano, é para salientar a estrutura orgânica, a configuração estática e estritamente funcional ou quantificável do corpo” (2001, p. 386). Por isso, o termo Körper detém uma importância clara para o entendimento de corpo para Husserl. Ele contrapõe Körper ao termo Leib. Esse vocábulo (Leib) é apresentado por Husserl como algo vivo, o corpo próprio. 
Uma vez diferenciados os termos de Körper e Leib muitos seguidores de Husserl utilizaram e de certo modo aperfeiçoaram esses conceitos, claro que, cada um dentro da sua proposição fenomenológica ${ }^{1}$. Henry também foi um grande leitor de Husserl, porém, sua maior influência sobre este tema deriva do grande pensador francês Maine de Biran. Segundo Henry, os demais pensadores criaram diversas teorias sobre o corpo, porém, elas o narram como pertencendo apenas ao mundo, à exterioridade. Diante disso, Henry afirma que o primeiro filósofo a colocar a questão do corpo na longa história da reflexão humana e "compreender a necessidade de determinar originariamente nosso corpo como corpo subjetivo, foi Maine de Biran” (2012, p. 18. Grifo do autor).

A presente pesquisa não tem por objetivo fazer um estudo histórico tampouco comparativo, mas busca mostrar a tese sobre o corpo subjetivo em Michel Henry que ao aprofundar este tema, fez algumas aproximações e distanciamentos com outras teorias. A crítica acaba sendo predominante em seus escritos, por ele não concordar com a maneira como o corpo era lido e interpretado pela fenomenologia histórica, ou seja, como objeto do mundo, como um fora de si mesmo, sempre visto a partir da exterioridade, desta forma, a vida subjetiva era totalmente esquecida e excluída do pensamento fenomenológico.

Por isso, para abordar a teoria do corpo em Michel Henry se faz necessário primeiramente discorrer sobre a imanência absoluta, pois nela manifesta-se a subjetividade primordial. Acredito ser esse um dos pontos centrais para compreender a filosofia henryana. A imanência absoluta é um dos assuntos centrais de seu pensamento filosófico fenomenológico. As duas grandes obras Filosofia e Fenomenologia do Corpo e $L$ 'essence de la manifestation devem ser lidas conjuntamente, sem recortes e interrupções, embora na segunda, a noção de corpo não apareça com muita força, ou sendo mais preciso, pouco aparece, se faz presente implicitamente nos conceitos apresentados. Então, é justo iniciar o estudo a partir da imanência, pois raciocina sobre corpo imanente e objurga o transcendente.

Por fim, alerto o leitor que não será trabalhado o tema da "Encarnação" desenvolvido posteriormente por Henry em suas outras grandes obras. Não por haver uma ruptura entre as temáticas, mas sim, uma diferença na forma como o assunto do corpo foi tratado. $\mathrm{Na}$ "Encarnação" o termo corpo, foi explorado e aprofundado com outra noção: a da carne.

\section{Teoria da imanência}

A proposição defendida pelo autor em pauta será a da imanência absoluta, a transcendência. O pensamento transcendente esqueceu-se da vida subjetiva encarnada, da imanência. Ao investigar o pensamento ocidental, Henry percebeu que esse problema era evidente não só na filosofia, mas também, nas demais ciências². Praticamente toda a tradição ocidental seguiu o esquema transcendental, e assim, mergulhou em uma profunda cegueira que provocou uma grande tensão no pensamento e na humanidade ${ }^{3}$. Para Henry é evidente que o pensamento científico não nota outras possibilidades, pois seu interesse investigativo não parte da vida subjetiva do indivíduo, mas, da exterioridade. Sustenta que, enquanto a humanidade confiar somente no pensamento científico, as barbáries aumentarão. E uma coisa é certa, nos tempos atuais, os conflitos e as crises não só tem

\footnotetext{
${ }^{1}$ O objetivo da pesquisa não é fazer um estudo histórico sobre o corpo, apenas enfatizo que os conceitos sobre esse tema foram desenvolvidos por Husserl influenciaram praticamente todos os fenomenólogos e as fenomenólogas.

2 Nesse estudo, estarei focalizado apenas na crítica à filosofia. A crítica dirigida as outras ciências, podemos encontrar em (HENRY, M. A barbárie. 2012). .

${ }_{3}$ A obra de Husserl que foi muito apreciada por Henry e por toda a tradição fenomenológica que discute profundamente o tema da crise. Cf. HUSSERL, E. A crise das ciências européias e a fenomenologia transcendental uma introdução à filosofia Fenomenológica. (2012).
} 
aumentado, mas assombrado cada vez mais a humanidade com o crescimento bárbaro das violências em todas suas dimensões. Diante disso, Henry chama a filosofia para a responsabilidade, deixando clara sua missão no mundo atual ${ }^{4}$.

A proposição central do fenomenólogo é pensar a vida, a ipseidade, por isso, critica demasiadamente a cegueira com que foi elaborado o pensamento que levou ao esquecimento da imanência subjetiva do ser do ego. Para contrapor essa teoria, elabora a partir da imanência sua estrutura interna e tudo o que ela manifesta a partir do seu poder originário. É recorrente nos escritos esse poder originário. Poder de ser e manifestar o seu ser. "À luz da idéia desse fim, a imanência pode ser entendida como essencialmente afetada por algo como impotência, pela impossibilidade” (HENRY, 2011, p. 419). A princípio, esse pensamento pode soar um pouco estranho aos ouvidos do leitor, por talvez, tentar compará-lo ao relativismo. Porém, a essência sendo imanente e não transcendente, é impossibilitada por ela mesma de manifestar outra coisa que ela não é. Isso porque na sua originalidade ela é e manifesta somente aquilo que traz na sua essência própria. Para Henry a impossibilidade é que determina "a relação original do ser com o soi significa, desde então, não simplesmente e em geral a impossibilidade da excedência mas, para ser, a impossibilidade de se exceder soi-même" (2011, p. 419. Grifo do autor"). A imanência se deixa compreender como essencialmente afetada somente por ela mesma. Sendo assim, ela rejeita tudo o que lhe é estranho, diferente dela mesma. O mantém junto a Si mesmo, ou mais precisamente, o Si a ele mesmo sem a possibilidade de afastar-se dele mesmo.

Esse modo de elaborar a imanência nos leva a refletir sobre as duas maneiras que o autor elabora para mostrar a absolutez imanente. Essa lógica do pensamento nos induzirá a concluir a impossibilidade do Si de sair de Soi même: no primeiro argumento Henry mostra a "impossibilidade de sair de si" (2011, p. 419). O pensador afirma e reafirma em diversos momentos essa mesma tese. O Si não pode 'sair para fora' de Si para ser outra coisa que não é na sua essência originária. Não pode também, relacionar-se como uma alteridade constituída pela exterioridade, ou fora dele ${ }^{5}$, pois a sua essência não comporta nada de diferente, estranho, mas somente a essência originária se manifesta. A relação constitui a partir do Si mesmo e se opõe a tudo que é diferente de Si, a toda a alteridade.

O segundo argumento está conectado com o primeiro pela impossibilidade de escapar daquilo que se é, de desatar-se da essência. Isso leva a Ipseidade ou cada Si a ser e a vivenciar a sua originalidade verdadeira. A singularidade é assumida e vivenciada pelo indivíduo e assim, constitui-se a essência a partir da imanência. Isso significa que a "impossibilidade aparece finalmente como não podendo se compreender que a partir desta positividade da relação original do ser consigo mesmo e isso que a funda, a partir da coerência da essência na unidade original que pertence a ela e a constitui” (HENRY, 2011, p. 421. Grifo do autor). A manifestação do Si mesmo não acontece fora de Si, na exterioridade. Por isso, Henry critica duramente o método da intencionalidade tradicional, em que, o ego primeiramente precisa constituir-se para num segundo momento fazer com que as coisas apareçam. Para Henry não, o que funda o ato de aparecer não é o ato intencional, mas a subjetividade pura. Aparece o que é.

Mais ainda, a impossibilidade quer dizer unidade, entre outras palavras o que foi atado ou amarrado nela e por ela não pode ser desatado. $O$ indivíduo não pode se desvencilhar-se de Si mesmo. O Si está impossibilitado de sair dessa unidade, está enlaçado a sua essência. Apesar deste não ser o momento para discorrer sobre o tema da liberdade, o ilustro brevemente para dizer que o pensador desenvolve e afirma que o Eu

\footnotetext{
Novamente, remeto a leitura da obra "A barbárie".

5 Esse argumento é desenvolvido em diversos momentos na obra a Essência da Manifestação, mas, que evoca com muita força o parágrafo 39 quando comenta a questão de Deus e a Déité no mestre Eckhart. Esse último conceito é a Unidade pura e não recebe nada de fora, do outro, do estranho é pura unidade.
} 
não é livre, sua liberdade não consiste em fazer escolhas fora de Si, mas de seguir o que a sua essência apresenta.

O pensador expõe com audácia que cada Si na sua singularidade deverá viver, experimentar profundamente o que a sua vida vivencia no momento. Mais precisamente, ser coerente dentro da sua unidade primordial consiste na fidelidade à estrutura interna da imanência. Para Henry ser preso dentro da estrutura interna pela sua essência, impossibilita o sair de Si, ou seja, exceder-se, recuar abaixo do seu ser e escapar de Si ou até mesmo negar-se a Si mesmo, essa impossibilidade significa que "identicamente seu apego irremissível a Si, o caráter irredutível do laço que o conecta a ele mesmo na relação original é o que o constitui" (HENRY, 2011, p. 421). O ser do ego não pode ser diluído, fracionado ou mesmo cortado em diversas partes. É o segredo, o mistério da singularidade. A vida é vivida a partir da interioridade e não da exterioridade. Embora, quando a exterioridade é predominante, vê-se o indivíduo a partir de um distanciamento que passa a ser contemplado e constituído pela terceira pessoa, ou pela exterioridade, tema veementemente rejeitado por Henry.

Diante das diversas impossibilidades, o pensador menciona alguns exemplos: de sobrevoar sobre o seu ser e o de considerar a partir da exterioridade, de se encontrar colocado ao exterior de Si e de ver-se a partir da exterioridade, enfim, de se retirar de Si (2011, p. 422). Enfatiza que o ser do ego constitui-se fora das categorias da consciência intencional ou representativa. O ser em questão situa-se por Si e não por uma consciência externa. Essa é uma das grandes críticas dirigidas por Henry à teoria do corpo tradicional.

Para Henry o ser-em-situação torna-se "contingente por relação ao ser e, muito mais, esta contingência é compreendida como aquela da situação” (2011, p. 423). O grande problema é que as teorias não percebem o que se passa no ser subjetivo, ou o percebem longinquamente. Então, o ser-em-situação constitui-se a partir da sua imanência pura e não o contrário. Remete a esse modo de pensar a teoria clássica do corpo desde uma sistematização teórica elaborada pela racionalidade. "Essa contribuição sintética do conjunto de determinações extrínsecas já eram visíveis na filosofia clássica do corpo" (HENRY, 2011, p. 423). Portanto, não é o sujeito constituído que tem a liberdade de escolher-se ou de negar-se. Quem o escolhe é a subjetividade absoluta, independente do seu querer ou não, a Vida já o escolheu anteriormente ${ }^{6}$.

\section{Corpo subjetivo}

A partir da imanência absoluta que deve ser elaborada a tese do corpo subjetivo. Henry organiza a proposição sobre o ser do ego, que não é mais determinado como "puro pensamento cuja essência se esgota no conhecimento da extensão e na contemplação das coisas, ela parece agora identificada com a ação, por meio da qual eu modifico incessantemente o mundo, mesmo que fosse apenas para tornar possível, nele, a continuação de minha própria existência” (HENRY, 2012, p. 70). Há uma quebra no modo de fazer fenomenologia do corpo, pois, a tarefa não parte da soberania do cogito para pensar sobre o corpo. Agora, o corpo não será mais lido e nem visto como um puro pensamento ou extensão. Henry drasticamente e ousadamente, inverte esse modo de pensar.

Ao interpretar o pensamento de Biran, afirma que o ser encarnado não constitui primeiramente o ego para depois instituir seu corpo. Pois, se assim procedesse, o corpo seria apenas um meio para o ego agir. O argumento da teoria do corpo subjetivo mostra que não há distinção entre o corpo e o ego. "Ele mesmo é esse corpo, ele mesmo é esse

6 Outro tema pertinente e muito trabalhado por Henry é a questão da passividade. Aqui, não temos como desenvolvê-lo, porém, ela é fundamental para compreender a noção da vida subjetiva. 
movimento, ele mesmo é esse meio. Ego, corpo, movimento, meio são a mesma coisa, e esta é bem real, não se dissolve na noite do inconsciente" (HENRY, 2012, p. 79). A unidade entre corpo e ego é muito bem trabalhada por Henry. A encarnação não é teórica, mas concreta, real. Evidencia a materialidade do sujeito, ou mais precisamente, o ser do ego. Critica duramente toda a filosofia da representação, porque essa faz referência ao indivíduo concreto, encarnado, mas o vê de modo idealizado, representado teoricamente. E uma vez idealizado pelo pensamento não há vida própria, subjetiva, mas constituída, pensada. Não é por acaso que ele faz uma advertência ao leitor sobre a vida material do sujeito, quando na "segunda edição francesa" da obra "Filosofia e fenomenologia do corpo" afirma o seguinte: "o leitor que tiver a paciência de me seguir até a conclusão descobrirá, especialmente, o projeto de uma reinterpretação do pensamento de Marx à luz da filosofia do corpo, que o autor dos Grundrisse chama, em muitas ocasiões 'subjetividade" (2012, p. 8). Isso significa que a filosofia do corpo deve ser compreendida a partir da imanência subjetiva material, concreta. Essa tese se contrapõe com a proposição do idealismo e mostra como a subjetividade deve ser pensada, a partir da vida concreta do ser em situação.

A determinação do ser originário de nosso corpo como subjetividade pura, a iluminação do caráter absoluto do conhecimento que se relaciona com esse corpo originário, uma vez que ele não é o conhecimento receptor de um ser transcendente, mas uma esfera de imanência radical, a ideia de um conteúdo absoluto (HENRY, 2012, p. 247).

A subjetividade constitui-se a partir do conteúdo que o Si encarnado revela aqui, e agora, no instante. Sendo assim, não existe a possibilidade de separar concretamente o ser do ego do corpo. Por isso, é importante a leitura e a compreensão da imanência absoluta, pois, percebe-se a unidade do Si como já foi mostrado nesse estudo. O autor insiste na não dualidade do mesmo, mas sim integração, plenitude. Isso significa que o indivíduo é assim por natureza e não porque foi unificado pelo pensamento.

Outro aspecto importante reputado fortemente pelo autor é o da concepção do corpo como objeto. O corpo não é pensado como um objeto, máquina ou coisa. Por ser um corpo sensível, ou melhor, corpo afetivo e que é ego, não pode ser um simples instrumento que estaria a serviço de um ego soberano e racional. Aqui, seria possível também aprimorar a pesquisa sobre a defesa da dignidade humana a partir do corpo subjetivo, visto que muitos regimes autoritários ou não, escravizam os corpos e os reduzem a meros objetos. Essas teses são rejeitadas pelo nosso autor porque por muito tempo esse pensamento prevaleceu na filosofia e nas outras áreas do conhecimento, sobretudo, nas ciências da saúde. O corpo quando visto como objeto necessita ser cuidado como uma máquina, pois, precisa estar bem para funcionar adequadamente, obrigatoriamente a manutenção deve ser feita regularmente. Essa é realizada por um agente externo que o vê assim, o regula e dessa maneira a 'máquina' funciona. Aqui, há uma quebra, uma ruptura com a tradição, pois, mostra uma subjetividade que é afetividade, vida, doação, carinho, amor. Se na tradição o corpo era considerado como uma coisa entre as coisas do mundo transcendente, agora passa a ser uma subjetividade e o centro da doação originária e absoluta.

A doação originária e absoluta é dada, revelada diretamente e sem nenhum distanciamento, não existe uma distância entre o ego e o corpo, porque há unidade. Também a doação é dada pela imanência interna. "Determinamos assim o ser originário do corpo como pertencendo à região na qual se realiza a revelação a si mesmo da intencionalidade, no âmbito da experiência interna transcendental” (HERNY, 2012, p. 92). Sustenta que a intencionalidade originária se dá na experiência interna transcendental, e revela o conteúdo verdadeiro. Não há uma mediação intelectual para fundar à verdade sentida. Apesar de Henry não rejeitar a fenomenologia tradicional, mostra que existe uma 
revelação anterior ao ato de intencionar que faz com que a vida apareça. Pode-se dizer que o ser é prioritariamente um aparecer. Porém, a tarefa da fenomenologia constitui-se a partir do aparecer puro, mostrar a manifestação do ente tomando em consideração o seu modo de aparecer mais do que o aparecer propriamente dito. Por isso Henry assinala os limites da fenomenologia histórica e busca responder em que consiste essa matéria fenomenológica da fenomenalidade. Contesta sua doação que na fenomenologia material é caracterizada pela fenomenalização da fenomenolidade pura em seu devir afetivo como subjetividade pura.

Um dado imanente no sentido da redução, no sentido do que é visto e
captado em si mesmo na evidência da vista pura - ainda que não pertença a
imanência real da cogitatio, pois se encontra situado fora dela. Nesse caso,
fica claro o sentido deste 'ainda que'; é porque está incluído na cogitatio
com um elemento real desta e a condição de não estar pelo que a essência
genérica e (particularmente a da cogitatio) é suscetível de fazer-se tal dado
absoluto em qualidade do visto puro por (mor) meio do ver, em qualidade
de e-videncia. Faz-se patente deste modo, nesta vinda do gênero a vista
pura. Na segunda prova: que a extensão do dato puro implica sua liberação
da cogitatio, sua vinculação a evidencia, sua definição ao mesmo tempo como
objetividade e não já com subjetividade (HENRY, 2009, p. 137. Grifo do autor).

O grande problema da fenomenologia intencional de Husserl é intuir o conhecimento originário, que Henry demonstra insistentemente desvelar apenas um modo de aparecer, o da vista pura, enquanto a imanência subjetiva como dado absoluto fica de fora. $\mathrm{O}$ autor reconhece a dupla significação do termo aparência que observa a tese hussuerliana tanta aparência, quanto ser, entende por aparência o conteúdo daquilo que de certo modo aparece. Sua aparição é o aparecer mesmo enquanto tal e permanece indeterminado, por isso, este princípio adquire na fenomenologia material a seguinte reformulação: tanto aparecer, quanto ser. "Tanta aparência, quanto ser, é equívoco em virtude da dupla significação do conceito de aparência, que significa tanto o que aparece como o seu aparecer. Por conseguinte, reformula-se o princípio assim: tanto aparecer, quanto ser" (HENRY, 2008, p. 3. Grifo nosso). Sendo assim, Henry consegue pensar a subordinação de toda a ontologia à fenomenologia prévia. Na medida em que o aparecer aparece e, por esta razão, o ser é, tem a mesma essência. O autor "sustenta a tese de que o aparecer da vida não faz aparecer nada de outro, nada de outra coisa, de um ente, mas a própria vida, que por sua vez é o seu autoaparecer, nua, ou seja, desprovida de qualquer conceito” (GRZIBOWSKI, 2016, p 185).

Ainda sobre o método fenomenológico histórico Henry aponta outro problema, a dificuldade de ver o invisível. "Existe assim, uma autodoação fundamental da qual a realidade fenomenológica é um pathos, uma afetividade que chamo transcendental - como se chamou transcendental a consciência que torna possível o mundo e os objetos. Essa efetividade é um pathos que é a Vida e a sua carne fenomenológica é feita de uma espécie de oscilação entre a alegria e o sofrimento" (HENRY, 2004, p. 20. Por isso, Henry fala da unidade da vida e que ela se revela no seu próprio aparecer e não no tempo ex-tático. Esses temas serão desenvolvidos e aprimorados em outros textos como, por exemplo: nas tonalidades afetivas da alegria e do sofrimento. Maravilhosamente diz que, ninguém nunca viu a alegria ou o sofrimento por serem invisíveis aos nossos olhos. "Na ausência de todo o afastamento interior do sofrimento, a possibilidade de dirigir sobre ele um olhar, é excluída. Ninguém nunca viu seu sofrimento, sua angústia ou sua alegria. O sofrimento como toda a modalidade, é invisível”. (HENRY, 2004, p. 33). Esse é o segredo da fenomenologia de Henry, a imanência absoluta ao revelar-se na invisibilidade. Sendo assim, o corpo subjetivo não pensa o pensado (cogito-cogitatum), mas vive e experimenta, prova ele mesmo a vida, as coisas que são invisíveis. Como os afetos, os amores, os prazeres, as carícias. 
Todo o ser de nosso corpo se reduz a seu ser constituído pela subjetividade da vida absoluta e, fora desse fenômeno não existe outro corpo a não ser da consciência que pensa e o constitui. Conforme descrito neste estudo, o corpo subjetivo é um corpo vivenciado, sentido e existe porque é sentido para posteriormente ser descrito.

\section{Corpo transcendental}

O que caracteriza o corpo subjetivo é a imanência absoluta que ele chama de vida encarnada de um ser concreto. A subjetividade não é uma ideia de um elemento impessoal e vazio, também não pode ser um nada por ser uma abstração. Sendo assim, a subjetividade opõe-se a tudo o que é abstrato. Na visão de Henry "o que é abstrato é o que é transcendente" (2012, p. 227). Isso não condiz com a subjetividade encarnada, pois ela constitui-se por um conteúdo vivo e que fornece elementos para o ser transcendente. Antes de existirem, os conteúdos transcendentes são imanentes, estão presentes e são vivenciados pelo ser do ego. Por isso, Henry afirma em diversos momentos que a vida não precisa de formas, regras ou da ciência para saber o que ela mesma é, ou como vivê-la, se conhece com sua própria sabedoria.

Então, a análise ontológica fenomenológica do corpo subjetivo, mostra que há um corpo subjetivo e uma sabedoria própria que é dele mesmo. É anterior, primordial ao ato de aparecer e não pode ser eliminada pois, é um poder que se manifesta em cada Si singular, em cada vivente.

A admissão da possibilidade e da existência de um conhecimento humano absoluto é o que Henry chama de monismo ontológico, ou seja, "a concepção em virtude da qual alguma coisa real só pode nos ser dada em geral no elemento do ser transcendente” (2012, p. 229). O grande problema instaurado pelo monismo ontológico foi ter apresentado e seguido uma única forma de conhecimento. Assim, esvaziou outras possibilidades e com isso exauriu a subjetividade. O mesmo problema foi aplicado na concepção sobre o corpo. "O monismo ontológico teve esta conseqüência decisiva que impediu constantemente a reflexão filosófica de se elevar até a ideia do corpo subjetivo" (HENRY, 2012. p. 230. Grifo do autor). Henry afirma que o monismo ontológico vem desde a filosofia grega e passa por todos os períodos, porém, no período moderno a "sua forma é de consciência" (KOWALSKA, 1980, p. 33). O conteúdo do corpo foi submetido ao aparecer externo da consciência. E a visão que é composta a partir da exterioridade está associada à visibilidade, quer dizer no modo como se dá o fenômeno exterior, no mundo, isso porque o mundo é visível pela e na exterioridade. Sendo assim, critica exaustivamente as ciências, pois elas objetivam e exigem que o eu e todos os outros "egos" possam aparecer na exterioridade do mundo, e que todo o fenômeno passe a ser visto. Assim, a interioridade desaparece completamente.

Essas teorias, como a da fenomenologia transcendental, constituem o corpo como ser transcendente, esquecem que antes do ser transcendente há um ser subjetivo o qual se difere dos livros, canetas, mesas. O corpo subjetivo é um corpo orgânico, metodologicamente submetido e reduzido ao ser transcendente. Porém, o corpo originário tem suas características próprias. Fenomenologicamente deve-se perceber que possui suas intencionalidades primordiais. A partir da teoria transcendental ele é lido como uma coisa do mundo. Fez-se uma inversão, porque o nosso corpo está antes de qualquer teorização situado no mundo. Uma vez situado no mundo, não significa que é do mundo, apenas se relaciona com ele e com esta ou aquela determinação do ser transcendente. Para Henry, "manter tal relação com o mundo, no entanto, não é pertencer, como uma coisa pertence ao seu elemento. Nosso corpo só pode estar no mundo sob a condição de não ser nada do mundo. É porque ele é subjetivo que nosso corpo é situado” (2012, p. 232). 
Para a filosofia da subjetividade não se deve abandonar o corpo subjetivo para inseri-lo no mundo. Ao contrário, o que permite nossa inserção no mundo é a nossa subjetividade.

Para concluir este ponto, Henry chama atenção para a linguagem utilizada pelo monismo ontológico onde se desloca o "Eu subjetivo" para um "Eu externo". De modo que as análises sobre o corpo são realizadas pela terceira pessoa. Evidencia essa teoria com a seguinte frase: "tenho um corpo" (2012, p. 238). Essa linguagem é utilizada pelo monismo ontológico e vê o corpo como exterioridade. Pode-se dizer eu tenho um corpo, embora saiba previamente que ele está submetido ao corpo absoluto. Contrapõe-se com o seguinte enunciado: "Eu sou meu corpo" (2012, p. 239). Isso significa ser exatamente o que sou, na originalidade de meu corpo, na vida absoluta do meu ego.

\section{Considerações finais}

A proposição defendida no presente texto é de que o corpo subjetivo parte da imanência absoluta. Fora disso, torna-se difícil constituir a noção de corpo na filosofia. Por isso, não se nega a ideia da existência do corpo transcendental. Existem duas concepções de corpos, o transcendente e o subjetivo, embora, esses sejam o mesmo corpo. Assim, na teoria do corpo subjetivo, não se pode falar que existem duas maneiras de ver o corpo, como a exterior e a interior. "Não vejo meu corpo do exterior porque não estou jamais fora de meu corpo, eis o que devemos afirmar se quisermos conferir sentido às palavras e à teoria segundo a qual o ser de meu corpo pertence a uma esfera de uma imanência absoluta” (HENRY, 2012, p. 149. Grifo do autor).

Isso é o que Henry reclama e procura contrapor às diversas teorias fisiológicas e transcendentais acerca da compreensão do corpo. Henry apóia-se no argumento do ser originário do corpo e que a unidade de pertencimento do corpo transcendente ao ego se constitui com base no ser originário do corpo subjetivo, com base em sua unidade e em seu pertencimento ao ego, isto é, em determinações ontológicas que são originariamente um privilégio exclusivo de determinada região ontológica, "que é uma região de imanência absoluta” (2012, p. 150).

O corpo transcendental que nos abre ao corpo sentido, "trata-se do nosso ou ao das coisas, repousa, sobre uma corporeidade muito mais originária, transcendental num sentido último, não intencional, não sensível, cuja essência é a vida” (HERNY, 2014, p. 173). Essa é a grande tese defendida por Henry. O corpo subjetivo no sentido último ou primeiro. Ele que dará toda a materialidade fenomenológica para filosofia e para as ciências. Na primeira leitura e fora do contexto da fenomenologia talvez essa teoria soe estranha, como um conceito vazio de sentido e conteúdo. Porém, ao ser minuciosamente trabalhada por Henry, adquire força e originalidade.

\section{Referências}

DEPRAZ, Natalie. "La traduction de Leib, une Crux Phaenomenologica”. In: HUSSERL, Edmund. Sur L’intersubjectivité I. Ed. Natalie Depraz. p. 386-387. Paris: Épiméthée, 2001.

HUSSERL, E. Sur l'intersubjectivité I. Paris: Épiméthée, 2001. P. 386-387.

GRZIBOWSKI, Silvestre. Fenomenologia da subjetividade: vida, corpo e o cuidado ético em Michel Henry. In: CESCON, Everaldo (org.). Etica e Subjetividade. Petrópolis: Vozes, 2016.

HENRY, Michel. A barbárie. Trad. Luiz Paulo Rouanet. São Paulo: É Realizações Editora, 2012.

HENRY, Michel. Encarnação: uma filosofia da carne. Trad. Florinda Martins. Portugal: Círculo de Leitores, 2000. 
HENRY, Michel. Auto donation. Entretiens et conferences. Paris: Beauchesne, 2004

HENRY, Michel. Fenomenología material. Trad. Javier Teira y Roberto Ranz. Madrid: Ediciones Encuentro, 2009.

HENRY, Michel. Filosofia e fenomenologia do corpo: ensaio sobre a ontologia biraniana. Trad. Luiz Paulo Rouanet. São Paulo: E Realizações Editora, 2012.

HENRY, Michel. Fenomenologia não-intencional. Trad. José Rosa. LusoSofia: Press, 1992. Disponível em: www.lusosofia.net.

HENRY, Michel. L'essence de la manifestation. Paris: PUF, 2011.

HENRY, Michel. O começo cartesiano e a ideia de fenomenologia. Trad. Adelino Cardoso. Covilhã: LusoSofia: Press, 2008. Disponível em: www.lusosofia.net.

HENRY, Michel. Phénoménologie de la vie. Tome IV Sur l'éthique et la religion. Paris: Puf, 2004.

HUSSERL, E. A crise das ciências européias e a fenomenologia transcendental uma introdução à filosofia Fenomenológica. Trad. Diogo Falcão Ferrer. Rio de Janeiro: Forense universitária, 2012.

LECLERCQ, Jean. "Ter dois corpos”: vida, afetividade e sexualidade em Michel Henry. Trad. Maria Cândida Teixeira. In: ANTÚNEZ, Andrés Eduardo Aguirre; MARTINS, Florinda; FERREIRA, Maristela Vendramel (Orgs.). Fenomenologia da vida de Michel Henry: interlocução entre filosofia e psicologia. São Paulo: Escuta, 2014, p.173-193.

KOWALSKA - DOUFOUR, Gabrielle. Michel Henry un philosophe de la vie de la praxis. Paris: Vrin, 1980. 